\title{
The BDA; together
}

\author{
Martin Woodrow \\ Chief Executive BDA
}

The BDJ Upfront section includes editorials, letters, news, book reviews and interviews. Please direct your correspondence to the News Editor,

Kate Quinlan at k.quinlan@nature.com. Press releases or articles may be edited, and should include a colour photograph if possible.

W ith the Prime Minister's recent shift in focus to 'staying alert', the debate in the dental community inevitably moved ever further towards how and when dentistry eases out of the current restricted model of care. Thousands of questions follow. How safe is it going to be? What sort of dentistry can we provide? How many patients can we see? Will they want to come to see us?

Whilst this feels like the right time to look forward (with a sense of anxiety or optimism depending on your perspective) it also seems like a moment to take stock and look back at the past couple of months. Everything has been happening at such a pace that we haven't really had time for reflection.

Against a backdrop of uncertainty and a need to move at speed, the dental profession has done itself proud in responding to the challenge of organising and supporting the provision of urgent care across the four nations of the UK. Dentists and their teams have also pulled behind the wider NHS effort and we've been delighted to feature stories of dentists providing help and volunteering in a variety of roles from delivering meals to working on acute medical wards.

I'm also proud of the work that the BDA has done to support the profession during this extraordinary period. Like everyone else, we have adapted to unusual circumstances, providing advice and assistance from various home offices, kitchen tables or in my own case, a hut in the garden. It is testament to our staff and elected members that normal or even enhanced service has been delivered. Real teamwork has seen us secure a safety net for practice owners, associates and dental teams through temporary NHS contractual frameworks. These aren't necessarily perfect and frustrations remain about some unanswered questions, but these are beneficial arrangements agreed at pace and we work on to create ever greater certainty.

Our lobbying work has also been intense. We managed to get more than a hundred MPs to press the Chancellor to offer real support to self-employed dentists and private practices. We gathered evidence from thousands of members and made the case direct to ministers and media on private dentistry left exposed by the lack of government support. And with your help, we gained widespread coverage over the shortfall in personal protective equipment in urgent dental care centres. All of that work has relied on BDA members providing us with the evidence to make the case; another aspect of this period has been the fantastic active engagement from dentists in support of the arguments that we have been seeking to advance.

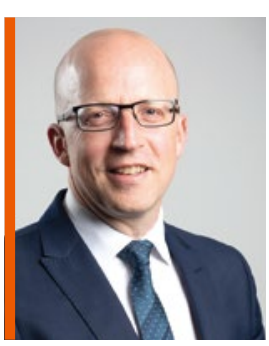

\section{'Against a backdrop of uncertainty and a need to move at speed, the dental profession has done itself proud'}

Engagement with our advice and information has also been phenomenal. Traffic across the BDA website for the last three months has been at unprecedented levels, with 2.6 million page views during April and May, and 25,000 daily views for our coronavirus updates. It's clear that our constantly updating of information has been well received.

Members have also clearly appreciated our one-to-one advice, with calls and emails to our expert advisors at around five times their usual levels. We have introduced new services responding to new needs. Our associate pay dispute resolution service was launched to ensure fair and satisfactory resolution for all parties and has received hundreds of queries. We've developed a new calculator to assist with furloughing staff and have seen over 2,000 downloads of our pandemic risk assessment guidance tool.

It has been rewarding to see the number of positive comments coming in from members and indeed from others, and the gratitude for our work. We know how difficult and uncertain the world of dentistry is right now so we are in turn hugely grateful to our members for continuing to support us, enabling us to do our best to continue to support and represent you.

At the moment there is certainly no letting up on that job. Elsewhere in this edition of the Journal, Chief Dental Officer for England Sara Hurley turns her thinking to what a new, and potentially better, normal will look like for dentistry. Her emphasis on breaking the link between NHS treatment activity and 